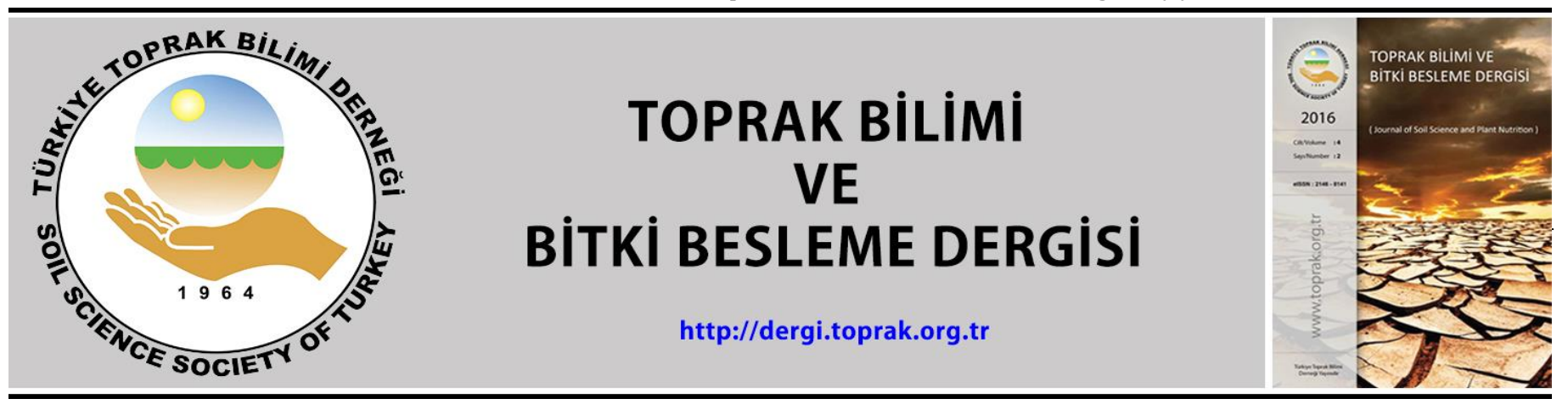

\title{
Ultramafik topraklardaki Alyssum Pateri subsp. Pateri bitkisinin ekolojisi ve ağır metal tolerans sınırının belirlenmesi
}

\author{
Turgay Dindaroğlu, Emre Babur *, Bülent Laz
}

Kahramanmaraş Sütçü İmam Üniversitesi, Orman Fakültesi, Orman Mühendisliği Bölümü, Kahramanmaraș

\begin{abstract}
Özet
Günümüzde sağlıklı gıda temininin önündeki en büyük engellerden birisi küresel bir sorun haline gelen toprak kirliliğidir. İnsan etkisi ya da anakayanın ayrışması sonucu topraklardaki ağır metal konsantrasyonun artması toprak kirliliğinin başlıca kaynaklarını oluşturmaktadır. Genel olarak Ultramafik regolitlerden oluşan topraklar, nikel veya mangan gibi ağır metallerin hiperakümülasyonu gibi özel adaptasyonlara sahip bitkilere ve yüksek endemizm floralarasına sahip olduğu bilinmektedir. Genellikle bu bitkiler besin elementi eksikliği veya fitotoksik iz elementlerine özellikle yüksek nikel (Ni) konsantrasyonlarına sahiptir. Bu araștırma hiperakümülatör olarak bilinen Alyssum pateri subsp. pateri bitkisinin farklı bir yetişme ortamındaki ekolojisi ve ağır metal tolerans sınırının belirlenmesi amacıyla Kahramanmaraș İlinde yürütülmüștür. Araștırma bulgularına göre ultramafik jeoekolojisinin aynı makro iklimde ve fakat değişik coğrafyalarda faklı özelliklere sahip olabildikleri anlaşılmıștır. Topraktaki toplam nikel (Ni) miktarı ortalama 7.08 ppm iken Alyssum pateri subsp. pateri bitkisinde en yüksek Ni miktarı 4061.27 ppm, bitkinin üzerindeki gal oluşumunda ise 3653.62 ppm olarak tespit edilmiştir. Toplam Ca konsantrasyonu toprakta 1735.70 ppm iken, bitkide ortalama 21268.88 ppm, gal olușumunda ise 21013.98 ppm olarak belirlenmiștir. Araștırma alanında Alyssum pateri subsp. pateri bitkisinin genel hiperakümülatör özelliğine ek olarak bitkide meydana gelen gal oluşumlarının da bitki kadar hiperakümülatör özellik taşıdığı ortaya konulmuştur. Endemik bitki türlerini bolca bulunduran bu alanlar koruma altına alınmalıdır. Başta madencilik, tarım ve tıraşlama kesimleri vb. ekosistemi strese sokacak faaliyetlerden kaçınılmalıdır. Ağır metal toplayıcı bitki türlerinin ise jeoekolojisi araştırılmalı ve fitoremediasyon bitkileri olarak ağır metalce yoğun alan toprakların ıslahında kullanımına önem verilmelidir.
\end{abstract}

Anahtar Kelimeler: Edafik endemizm, Adaptasyon, Edafik flora, Hiperakümülatör, Ekstrem ekosistemler, Alyssum

\section{Determination of the ecology and heavy metal tolerance limits of Alyssum Pateri subsp. Pateri growing on ultramafic soils}

\begin{abstract}
Today, one of the major global problems facing healthy food supply is soil pollution. Soil pollution caused by human is an important source of this problem, while soil pollution caused by heavy metals caused by decomposition of the bedrock is another part of the basic problem. In general, soils composed of ultramafic regolites are famous for hosting plants with special adaptations such as nickel or manganese hyperaccumulation and flora with a high level of endemism. It usually has nutrient deficiency or phytotoxic trace elements, especially high nickel concentrations. This research was carried out in Kahramanmaraş Province to determine the ecology and heavy metal tolerance limit of Alyssum pateri subsp. pateri plant known as nickel (Ni) accumulator. According to the research findings, it is understood that ultramafic geoecology can have different characteristics in the same macro climate but in different geographies. While total Ni content in soil was 7.08ppm, Ni content of Alyssum pateri subsp. pateri plant was 4061.27 ppm and $3653.62 \mathrm{ppm}$ in gal formation. While the total calcium (Ca) concentration was $1735.70 \mathrm{ppm}$ in soil, it was determined as $21268.88 \mathrm{ppm}$ in plant and $21013.98 \mathrm{ppm}$ in gal formation. In addition to the general hypercumulatory properties of Alyssum pateri subsp. pateri plant, gal formation occurring in the plant has hyperacumulatory properties as much as the plant. These areas with high endemism should be protected and some activities such as mining, agriculture and clear cutting that put stress on the ecosystem should be avoided. Geoecology of heavy metal accumulator plant species should be investigated and phytoremediation processes should be analyzed and recycled.
\end{abstract}

Keywords: Edaphic endemism, Adaptations, Edaphic flora, Hyperaccumulators, Extreme environments, Alyssum

(C) 2019 Türkiye Toprak Bilimi Derneği. Her Hakkı Saklıdır

\footnotetext{
* Sorumlu yazar:

\# Bu makale "II. Çanakkale Tarımı Sempozyumu"nda (14-15 Aralık 2017 Ziraat Fakültesi/Çanakkale) poster bildiri olarak sunulmuş olup, sempozyum bildiri özetleri kitapçığında benzer özeti basılmıștır.
Tel.
05309641771
Geliş Tarihi
22 Eylül 2019
5 Kasım 2019
e-ISSN
2146-8141
Kabul Tarihi
DOI : $10.33409 /$ tbbbd.668650 


\section{Giriş}

Toprak-bitki ve su ekosistemleri sürekli birbirleri ile etkileşim halinde oldukları için topraklardaki ağır metallerin bitkilere ve sulara karıșması hem bitkisel verim ve ürün kalitesi üzerinde hem de sucul ekosistemlerin kalitesine ve hatta dolaylı olarak insan sağlığı üzerinde de çok önemli etkilere neden olmaktadır (Kocaer ve Başkaya, 2003).

Ağır metaller kayaçların mineral yapılarında doğal olarak bulunmaktadır. Anakayaların ayrışması sonucu oluşan topraklar, anakayanın türüne bağlı olarak bünyelerinde farklı oranlarda ve formlarda ağır metal bulundururlar. Ultramafik topraklar (yapısında yüksek oranda $\mathrm{MgO}$ ve $\mathrm{FeO}$ bulunduran kayaçlardan oluşan topraklar), farklı kimyasal ve fiziksel özellikler taşımaktadır. Tropik bölgelerdeki ultramafik topraklar ılıman ve Akdeniz bölgelerindekine göre elementel içerik, nem, organik madde miktarı ve toprak pedolojisi bakımından farklılık gösterebilir (Alexander, 2009; Vithanage ve ark., 2014). Bitki ve toprak mikroorganizmaları ultramafik toprakların edafik stres faktörlerini, diğer adaptasyonların yanı sıra, gerekli besin maddelerinin verimli bir şekilde alınması ve bazı fitotoksik elementlerin yüksek konsantrasyonlarının dışlanması veya tersine biriktirilmesi yoluyla tolere ederler (Palm ve Van Volkenburgh, 2014). Yüksek derecede endemik türlere sahip olan ultramafik topraklar, edafik endemizmin ekolojsinin belirlenmesi bilim insanlarına yeni araştırma ortamları sunmaktadır (Rajakaruna, 2004; Anacker, 2012). Yeni Kaledonya'da (Papua Yeni Gine, Solomon Adaları ve Fiji'yi de içeren Melanezya denilen Pasifik okyanusunun Okyanusya bölgesinde yer almaktadır) \% 83'ü ultramafik topraklarla kaplı bölgede, 2150 endemik tür tespit edilmiştir (Jaffré ve L'Huillier, 2010). Ultramafik kayaçların en önemli temsilcisi ofiyolitler (bazı mafik, ultramafik kayaçlar ile bazı derin deniz çökellerinden oluşan grup) hidratasyon nedeniyle serpantin'e (yeşil renkli kayaç) dönüşmüşlerdir. Serpantinit anakayalarından oluşan toprakların hemen hemen tamamı ă̆ır metaller bakımından zengindir. Bununlabirlikte, serpantinit anakayasının minerolojik, fiziksel ve kimyasal özellikleri bakımından olumsuz toprak koşulları oluşturması nedeniyle ekosistem olarak oldukça hassas alanların en önemlilerinden birisidir. Bitkiler için yetişme ortamlarında en etkili toprak özellikleri kimyasal olanıdır (Kruckeberg, 1985). Serpantinit topraklarında özellikle kalsiyum (Ca) miktarı düşük, magnezyum (Mg) miktarı yüksektir (Walker, 1948; Vlamis ve Jenny, 1948; Kruckeberg, 1954; Laz ve ark., 2018). Bu ise bitki beslenmesinde önemli bir gösterge olan düşük Ca:Mg oranı ile karakterize edilmektedir (Walker ve ark., 1955; Proctor, 1970). Serpantinli topraklar içerdikleri düşük Ca konsantrasyonu nedeniyle "serpantin sendromu" diye isimlendirilen olumsuz yetişme ortamı koşuluna neden olmaktadır (Vlamis ve Jenny, 1948; Proctor, 1971). Bununla birlikte serpantinit toprakları Ni, Co, Cr gibi ağır metaller ile yüksek oranda Mg ve Fe içermesine karşın $\mathrm{Ca}, \mathrm{K}, \mathrm{N}, \mathrm{P}$ vb. bazı esas bitki besin elementleri açısından ise fakirdir (Proctor ve Woodell, 1975; Brooks, 1987). Bu elementlerin yüksek konsantrasyonlarda bulunması bitki türleri için zehir etkisi oluşturur.

Serpantinit topraklarının organik madde miktarının ve fiziksel özelliklerinin (su tutuma kapasitesi, toz ve kil miktarı) zayıf olması nedeniyle tarımsal faaliyetler ve ormancılık uygulamaları açısından çok fazla tercih edilmezler (Brooks, 1987; Brady ve ark., 2005; Laz ve ark., 2018). Bu toprakların üzerleri genellikle çıplak ve vejetasyon açısından çok seyrek olsa da, flora açısından farklı endemik türler bolca bulunmaktadır (Brooks ve Yang, 1984; Batianoff ve Singh, 2001). Serpantinit alanlarında doğal olarak yetişen bitkilerin bu alanlara en iyi şekilde uyum sağladığı, ekstrem edafik koşullara, ağır metallere karşı direnç gösterdiği ve adapte olduğu belirlenmiştir (Kruckeberg, 1985; Kruckeberg ve ark., 1999; Reeves ve ark., 2001; Adıgüzel ve Reeves, 2002; Avcl, 2005; Özdeniz ve ark. 2017).

Son yıllarda topraklarda ağır metal sorununun giderilmesi veya şiddetinin hafifletilmesi için hiperakümülatör bitkiler yarımıyla kirletici ağır metaller topraktan uzaklaştırılmaktadır. Bu yönteme fitoremediasyon yöntemi denmektedir. Bu bitkilerin birkaçının bir arada kullanılması ile ağır metaller (Ag, $\mathrm{Cd}, \mathrm{Co}, \mathrm{Cr}, \mathrm{Cu}, \mathrm{Hg}, \mathrm{Mn}, \mathrm{Mo}, \mathrm{Ni}, \mathrm{Pb}, \mathrm{Zn}$ ), metalloidler (As,Se), radionükleidler (90Sr, 137Cs, 239Pu, 238U, 234U), ametaller (B) ve diğer organik bileşikler (Toplam Petrol Hidrokarbonlar (TPH), Polisiklik Aromatik Hidrokarbonlar (PAHs), Poliklorlu Bifeniller (PCBs), Pestisitler) olmak üzere birçok zehir eşiğine gelen maddeler ile mücadele edilebilmektedir. Taraxacum officinale (Karahindiba) ve Alyssum pateri subsp. pateri (Demetkevke) bitkileri buna örnek olarak verilebilir (EPA, 2000). Bu bitkilerin topraktan aldıkları ağır metallerin bir kısmı bitkinin vejetatif organlarında depolanmasının yanında bitki bünyesindeki enzimler aracılığı ile parçalanarak bozulmakta ve transpirasyon ile atmosfere verilmektedir (Aybar, 2015). Thlaspi, Urtica, Chenopodium, Polygonum sachalase ve Alyssum gibi bazı bitkiler $\mathrm{Cd}$, Co, $\mathrm{Cu}$, Ni ve $\mathrm{Zn}$... gibi ağır metalleri bünyelerinde biriktirebilmektedirler. Bu bitkilerin hafif ağır metal bulunan alanlarda yetiştirilmesi kirlenmiş toprakların temizlenmesinde dolaylı bir yöntem olarak kullanılabilmektedir (Mulligan ve ark., 
2001). Lasat (2000), normal bitkilerde 100 ppm olan Zn konsantrasyonunun Thlaspi caeruledcens bitkisinde 26000 ppm'in üzerinde birikime sahip olduğunu tespit etmiștir. Raskin ve ark. (1994) göre kuru yaprak ağırlıklarının \% 0,1'den fazla $\mathrm{Ni}, \mathrm{Co}, \mathrm{Cu}, \mathrm{Cr}$ veya $\% 1 \mathrm{Zn}$ ve $\mathrm{Mn}$ içeren bitkiler hiperakümülatör bitki olarak adlandırılmıştır.

Öncelikle Brassicaceae üyelerinin, Ni hiperakümülatör olduğu bilinmekle beraber farklı coğrafyalarda farklı tolerans aralıklarının bilinmesi adaptasyon yeteneklerini belirlenmesi açısından önemlidir. Ayrıca toprakta, bitkide ve gallerde ağır metal konsantrasyonlarının ve birbirleri ile olan ilișkilerinin saptanması türün ekolojisi açısından gereklidir. Bu çalışma Kahramanmaraş kent merkezine $20 \mathrm{~km}$ uzaklıktaki Denizli Köyü yeşil kuşak plantasyon sahasında (Ek-3) ultramafik anakayalar üzerinde oluşan topraklar üzerinde yoğun bir şekilde bulunan hiperakümülatör bitki olan Alyssum pateri subsp. pateri'nin fitoremediasyon potansiyelini ortaya koymak amacıyla ekolojisi, yetişme ortamı toprak özellikleri, ağır metal ve bazı bitki besin elementi konsantrasyonları belirlenmiştir.

\section{Materyal ve Yöntem}

\section{Çalışma Sahasının Genel Özellikleri}

Çalışma, Kahramanmaraş İlinin yaklaşık 20 km doğusundaki Denizli Köyü sınırları içerisinde bulunan Yeşil Kuşak Ek-3 Ağaçlandırma Sahasında gerçekleştirilmiştir. 2004-2005 yıllarında Kahramanmaraş-Gaziantep Karayolu üzerinde 1675 ha'lık alanda farklı türler kullanılarak ağaçlandırılmıştır (Şekil 1).

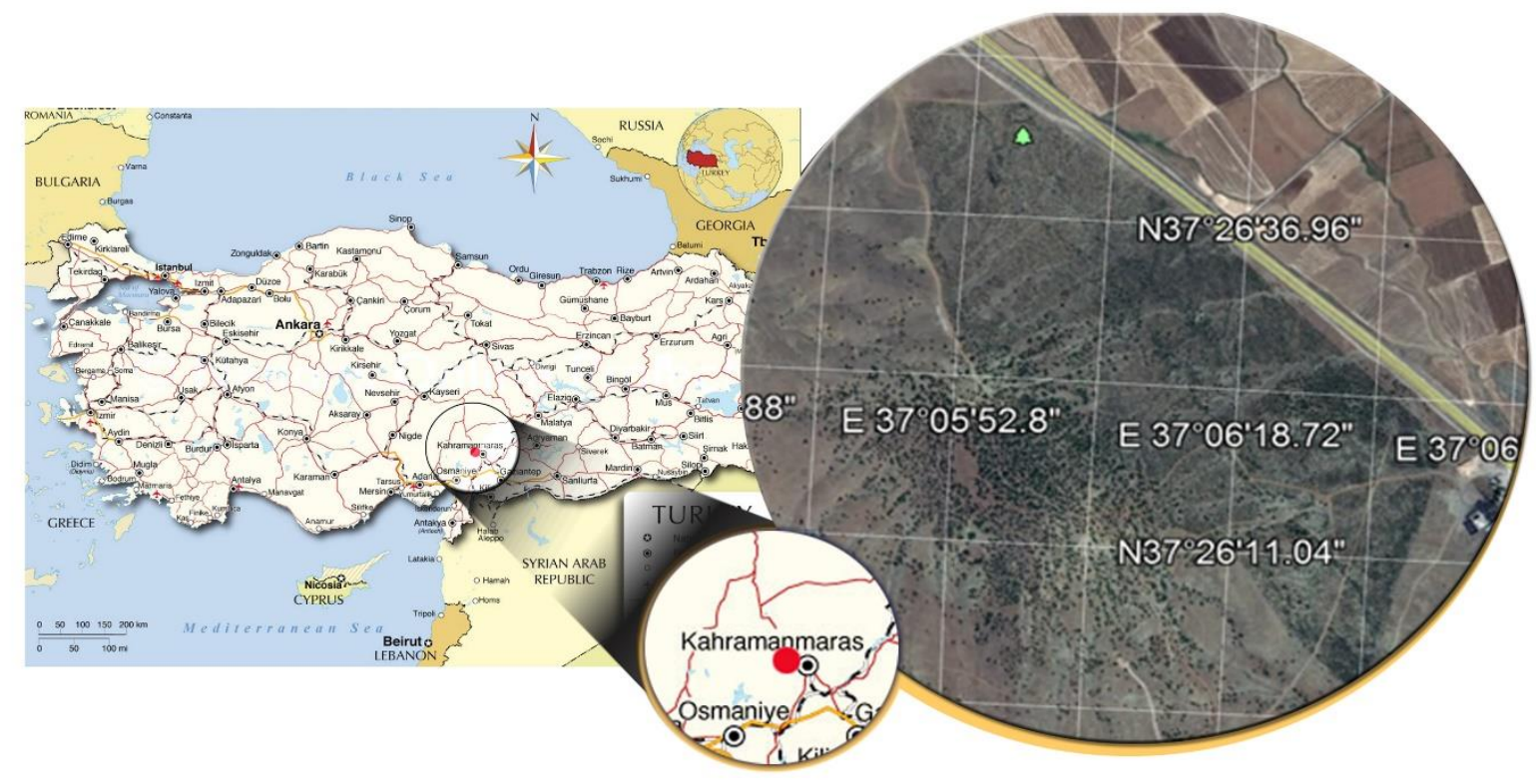

Şekil 1. Araştırma alanın konumu ve genel görünümü

Sahaya hızlı gelişen ve kuraklığa dayanıklı olduğu bilinen yabancı orijinli Pinus brutia var. elderica, yerel orijinli Pinus brutia, Pinus pinea, Cupressus sempervirens, Prunus mahalep, Pyrus communis, Pyrus elaegnifolia, Amygdalus sp. türleri dikilmiștir (Anonim, 1992). Ayrıca alanda doğal olarak yayılıș gösteren Quercus coccifera (Kermes meşesi) türü de çalı formunda bulunmaktadır. Otsu bitkilerden ise alanda bolca bulunan Alyssum pateri subsp. pateri, hiperakümülatör bitki türü mevcuttur. Alyssum pateri subsp. pateri, Brassicaceae familyasından Alyssum cinsine bağlı, çok yıllık ve sadece Türkiye'de doğal olarak serpantin anakayalar üzerinde yayılış gösteren endemik bir alttürdür. Ülkemizde özellikle iç Anadolu bölgesinde (Çankırı, Konya, Kayseri, Nevşehir) yaygın olan alttürün diğer yayılışları Kuzey Anadolu (Bolu, Kastamonu), Güney Anadolu (Antalya) ve Doğu Anadolu (Van, Erzincan, Ağrı) bölgelerinde yayılış göstermektedir. İranTuran flora bölgesi elemanı olan bu türün habitatı; çam ormanları, makilik alanlar ve bozkır vejetasyonudur. Dikey yayılışı ise 500 ile $3000 \mathrm{~m}$ arasındadır (Dudley,1965; Mutlu, 2012).

Araştırma sahası ortalama 650 m rakımda, \% 15-20 eğime sahip, ultramafik kayaçlar (serpantinit anakayası) alan üzerinde yaygın olarak bulunmaktadır. Akdeniz iklimi ile karasal iklim geçiş alanı üzerindeki araştırıma sahası sıcak ve ılıman iklim görülmektedir (Köppen-Geiger iklim sınıflandırmasına göre Csa). Alanın yıllık ortalama sıcaklığı $16,1^{\circ} \mathrm{C}$ dir. Temmuz ayı $28,1^{\circ} \mathrm{C}$ ile yılın en sıcak ayı, Ocak ayı ise $4,1^{\circ} \mathrm{C}$ ile en soğuk aydır. Yıllık ortalama yağıș miktarı $638 \mathrm{~mm}$ dir. Temmuz ayı $2 \mathrm{~mm}$ lik yağıșla yılın en kurak ay iken $118 \mathrm{~mm}$ ile Ocak ayı ise en fazla yağış alan aydır. Mutlak toprak derinliğinin 20-30 cm, fizyolojik derinlik ise maksimum $100 \mathrm{~cm}$ dir. 


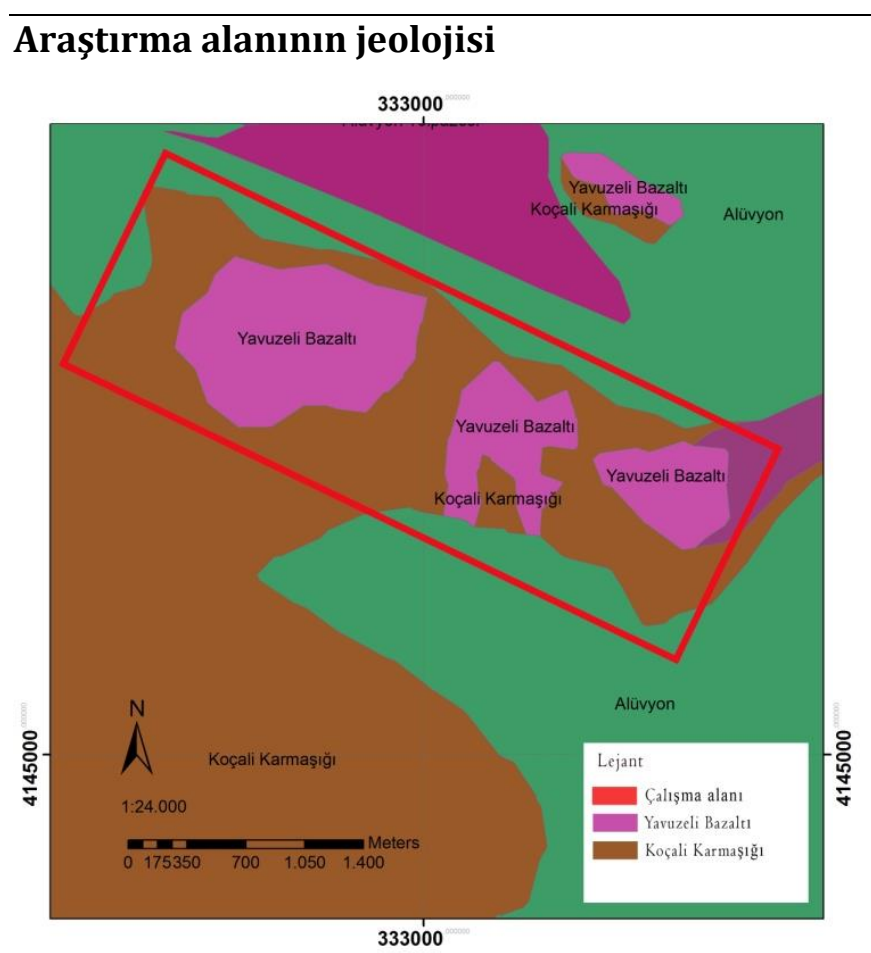

Şekil 2. Araştırma alanı formasyon haritası (M.T.A., 2015)
Araştırma alnında Koçali Karmaşığı ve Yavuzeli Bazaltı olmak üzere iki formasyon birbirinin içerisine sokulum göstererek yüzeylenmektedir (Şekil 2). Koçali Karmaşığı (JKk) Jura-Alt kretase dönemine ait (Ateş ve ark., 2008) kristalize kireçtaşlarından oluşmaktadır.

\section{Arazi Çalıșmaları}

Araştırıma sahasında Alyssum pateri subsp. pateri bitkilerinin yayılış gösterdiği yerlerden rastgele 5 deneme alanı belirlenmiş ve bu alanların içerisinden 100 er metre ara ile toprak ve bitki örnekleri toplanmıștır. Alınan toprak ve bitki örneklerinin fiziksel özellikleri KSÜ Orman Fakültesi Toprak ve Ekoloji Laboratuvarında, kimyasal özellikleri ise Doğu Akdeniz Geçit Kuşağı Tarımsal Araştırma Enstitüsü Toprak Laboratuvarında analiz edilmiştir. Çalışma sahasının anakaya teşhisinin yapılması için toprak numunelerinin alındığı noktalardan anakaya örnekleri toplanmış ve KSÜ Jeoloji Mühendisliği Bölümünde teşhis ettirilmiştir (Şekil 3).
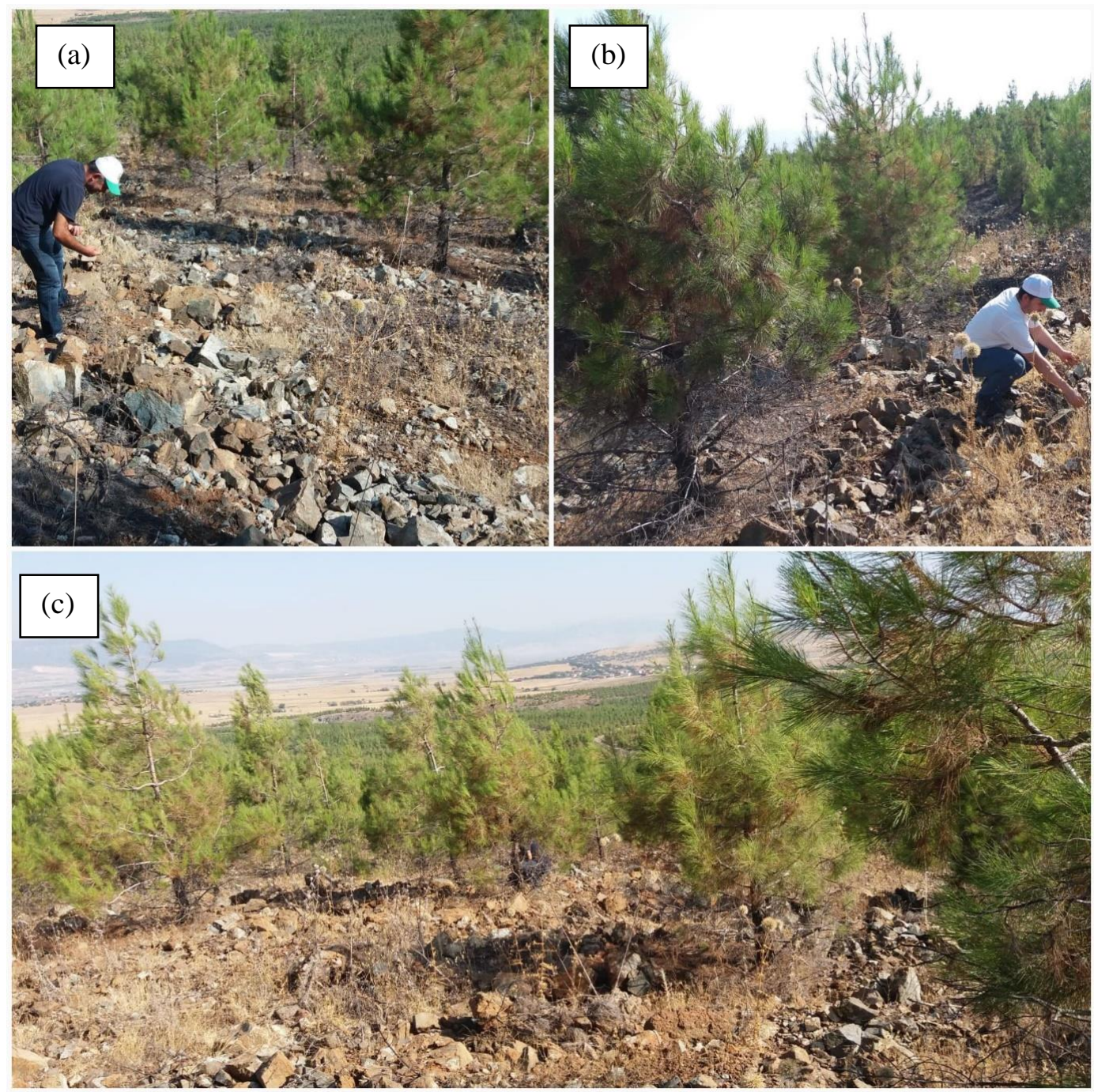

Şekil 3. Araştırma alanında (a) anakaya (Serpantinit), (b) bitki ve (c) toprak örnekleme noktalarından bazı görünümler 


\section{Alyssum Pateri Subsp. Pateri Bitki Örneklerinde Gal Oluşumu}

$\mathrm{Bu}$ bitkiler üzerinde Cecidomyiidae familyasına mensup gal sineklerinin bitki dokularını tahrip ederek yaralaması ve bitki üzerine yumurta bırakmaları üzerine küremsi, topuza benzer şekillerde galler meydana gelmektedir. Gal oluşumu genel olarak bitki dokularının tahribi ya da yaralanma neticesinde mikroorganizma ya da çeşitli böcek, akar gibi eklem bacaklıların yumurta bırakması sonucunda oluşan anormal gelişmelerdir. Gal oluşumuna sebep olan organizma, yalnızca özelleşmiş olduğu bitki de gal oluşumu meydana getirebilir. Bu bakımdan muhtemelen bitkiler kendi iletim demetlerine zarar veren bazı organizmaları belli bölgelere hapsederek bu zarardan kurtulmaya çalışmaktadırlar (Demirsoy, 1999). Araştırma alanında Alyssum Pateri Subsp. Pateri bitki örnekleri üzerinde Gal Oluşumu Şekil 4'te gösterilmiştir.

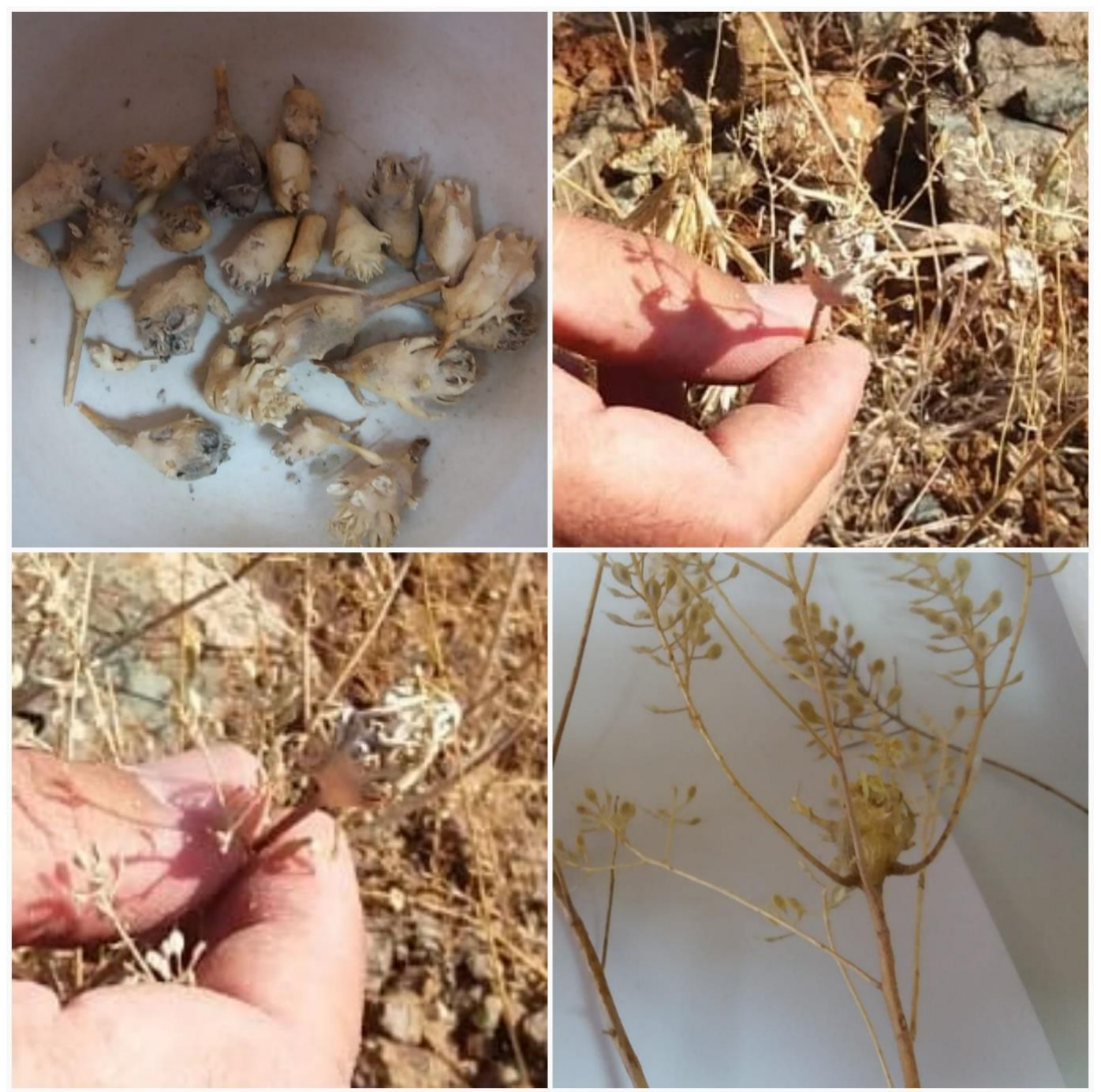

Şekil 4. Araştırma alanını büyük bir bölümünü kaplayan Alyssum pateri subsp. pateri bitkisi ve gal oluşumu.

\section{Laboratuvar Çalışmaları}

Araștırma sahasında 0-30 $\mathrm{cm}$ derinliğinden alınan toprak örneklerinin fiziksel ve kimyasal toprak özelliklerini belirlemek için hava kurusu hale gelinceye dek kurutulup, taş ve kökleri ayrılarak porselen havanda öğütülmüș ve $2 \mathrm{~mm}$ 'lik elekten geçirilerek, numuneler polietilen plastik poșetlerde saklanmıștır. Alınan toprak örneklerinde; nem içeriği (gravimetrik yöntem), tane çapı (Tekstür hidrometre (Bouyoucos, 1962), organik karbon (yaş yakma (Walkley-Black, 1934)), EC 1/5 toprak su çözeltisi (Janzen, 2004), pH (1:2.5) toprak su çözeltisi (Janzen, 2004) cam elektrotu metotları ile belirlenmiştir.

Bitki numuneleri sistematik olarak atılan noktalar tam ortaya gelecek şekilde $\left(20 \mathrm{~m} \mathrm{x} 20 \mathrm{~m}=400 \mathrm{~m}^{2}\right)$ alanlar belirlenmiş ve bitki örnekleri toprak ile birleștikleri yerlerden makas yardımı ile kesilerek toplanmıştır.

Topraklarda, bitkilerin gövde ve çiçek kısımlarında oluşan gallerdeki toplam makro ve mikro besin elementlerinden $\mathrm{Al}^{+3}, \mathrm{~B}^{+}, \mathrm{Ca}^{++}, \mathrm{Cd}^{++}, \mathrm{Co}, \mathrm{Cr}^{++}, \mathrm{Cu}^{+}, \mathrm{Fe}^{++}, \mathrm{K}^{+}, \mathrm{Mg}^{++}, \mathrm{Mn}^{++}, \mathrm{Na}^{+}, \mathrm{Ni}^{++}, \mathrm{P}+3, \mathrm{~Pb}^{2} \mathrm{Zn}^{++}$Agilent marka ICP cihazında ölçülmüştür (Anonim, 1982). 


\section{Bulgular ve Tartışma}

Araştırma alanı yüzey toprak örneklerinin laboratuvar sonuçlarına göre; topraklar kumlu killi balçık tekstüründe, toprak reaksiyonu hafif alkali olup, ortalama pH değeri 7.44 tür. Toprakların organik karbon içerikleri de oldukça düşüktür (\% 0.04-\% 1.82). Toprakların değişebilir Mg konsantrasyonu ortalama 1339 ppm olarak belirlenmiş ve oldukça yüksektir. Fosfor konsantrasyonu ortalama 3.82 ppm olarak belirlenmiştir.

Toprak örneklerinde toplam makro, mikro elementler ve ağır metal konsantrasyonları Mg (ortalama 498 ppm) haricinde diğer besin elementleri normal sınırlarda ve ağır metal konsantrasyonlarının ise Toprak Kirliliği Kontrol Yönetmeliğine (Anonim, 2019) göre düşük olduğu belirlenmiştir (Çizelge 1).

Topraklardaki Ca ve $\mathrm{K}$ besin elementi yüksek konsantrasyondaki Mg ile antogonistik bir etkileşime girdiğinden bitkiler tarafından alına bilirlikleri zorlaşmaktadır. Bu nedenle bu topraklarda yetişen bitkilerde Ca ve K besin elementi eksiklikleri görülebilir (Proctor, 1971). Serpantinit anakayasının bulunduğu alanlarda Ca konsantrasyonu genelde çok düşük bulunmaktadır (Proctor ve Woodell, 1975; Brooks, 1987). Ancak araştırma alanında "Koçali Karmaşığı" formasyonun ultramafik oluşumların içerisinde sokulum göstermesi sonucu genel kanaatin aksine yüksek bir Ca konsantrasyonu tespit edilmiştir (Şekil 5). Bu alanda Ca kaynağı Koçali Karmaşığı (JKk) Jura-Alt kretase dönemine ait (Ateş ve ark., 2008) kristalize kireçtaşlarıdır.

Çizelge 1. Toprak örneklerinde bazı toplam makro, mikro elementler ve ağır metal konsantrasyonları

\begin{tabular}{|c|c|c|c|c|c|c|c|c|c|c|c|c|c|c|}
\hline \multirow{2}{*}{ DA } & $\mathrm{Al}$ & $\mathrm{Ca}$ & $\mathrm{Cd}$ & Co & $\mathrm{Cr}$ & $\mathrm{Cu}$ & $\mathrm{Fe}$ & $\mathrm{K}$ & $\mathrm{Mg}$ & $\mathrm{Mn}$ & $\mathrm{Na}$ & $\mathrm{Ni}$ & $\mathrm{Pb}$ & $\mathrm{Zn}$ \\
\hline & \multicolumn{14}{|c|}{ ppm } \\
\hline 1 & 0.180 & 2035.24 & 0.01 & 0.34 & 0.01 & 0.50 & 9.78 & 204.96 & 512.83 & 6.06 & 7.98 & 8.85 & 0.06 & 0.28 \\
\hline 2 & 0.185 & 1697.71 & 0.01 & 0.16 & 0.02 & 0.44 & 6.48 & 97.88 & 505.44 & 4.48 & 10.89 & 4.97 & 0.11 & 0.30 \\
\hline 3 & 0.203 & 1910.62 & 0.01 & 0.42 & 0.01 & 0.62 & 9.65 & 123.85 & 511.22 & 10.38 & 11.58 & 7.97 & 0.19 & 0.35 \\
\hline 4 & 0.161 & 1664.78 & 0.01 & 0.07 & 0.01 & 0.37 & 4.44 & 84.69 & 504.61 & 2.08 & 9.34 & 4.00 & 0.03 & 0.23 \\
\hline 5 & 0.148 & 1370.19 & 0.01 & 0.27 & 0.01 & 0.33 & 7.59 & 138.86 & 454.10 & 5.18 & 6.26 & 9.62 & 0.08 & 0.33 \\
\hline
\end{tabular}

DA: Deneme Alanı

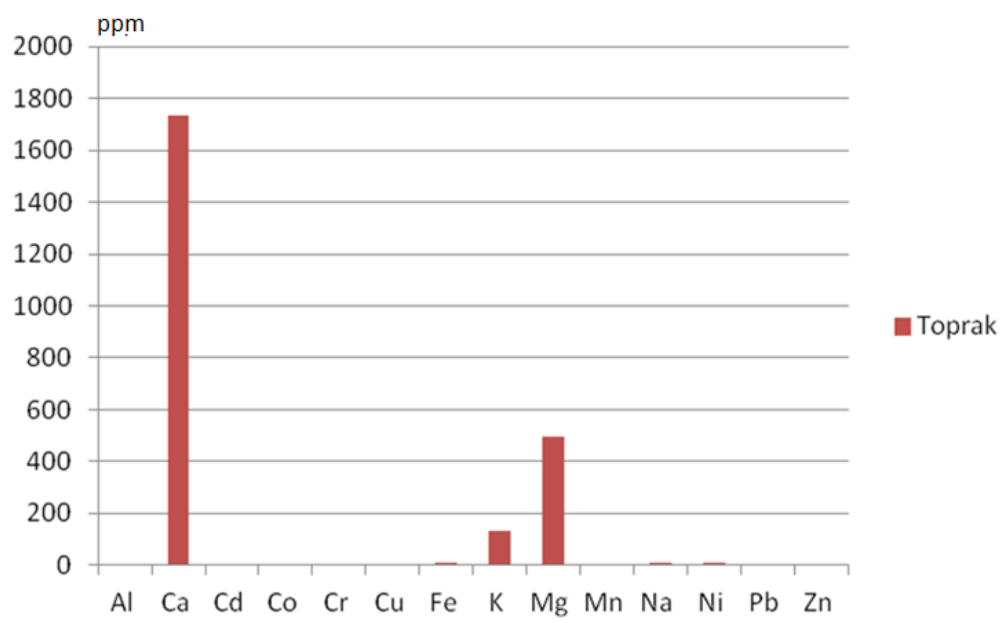

Şekil 5. Toprak örneklerinde bazı toplam makro, mikro elementler ve ağır metal konsantrasyonları

Topraktan bitkiye geçen ağır metal konsantrasyonları üzerinde en önemli etken bitki türü olmakla beraber, toprak özellikleri ve topraktaki ağır metal miktarı da önemlidir. Ayrıca bitkinin farklı organları da ağır metal birikiminde değişiklik gösterirler (Antonkiewicz ve Jasiewicz, 2002; Boyd, 1999). Bitki örneklerinde bazı toplam makro, mikro elementler ve ağır metal konsantrasyonları Çizelge 2'de belirtilmiştir.

Çizelge 2. Bitki örneklerinde bazı toplam makro, mikro element ve ağır metal konsantrasyonları

\begin{tabular}{|c|c|c|c|c|c|c|c|c|c|c|c|c|c|c|c|c|}
\hline \multirow{2}{*}{ DA } & $\mathrm{Al}$ & $\mathrm{B}$ & $\mathrm{Ca}$ & $\mathrm{Cd}$ & Co & $\mathrm{Cr}$ & $\mathrm{Cu}$ & $\mathrm{Fe}$ & $\mathrm{K}$ & $\mathrm{Mg}$ & $\mathrm{Mn}$ & $\mathrm{Na}$ & $\mathrm{Ni}$ & $\mathrm{P}$ & $\mathrm{Pb}$ & $\mathrm{Zn}$ \\
\hline & \multicolumn{16}{|c|}{ ppm } \\
\hline 1 & 397,55 & 39,80 & 22174,86 & 0,63 & 5,35 & 12,66 & 2,28 & 683,15 & 11226,73 & 1755,32 & 28,15 & 242,04 & 3874,76 & 2082,84 & 3,50 & 45,39 \\
\hline 2 & 224,51 & 27,65 & 16961,90 & 0,57 & 2,91 & 3,34 & 1,81 & 263,30 & 10479,40 & 1432,99 & 14,99 & 152,03 & 2999,20 & 1517,71 & 3,19 & 33,91 \\
\hline 3 & 243,72 & 28,90 & 19905,51 & 0,96 & 3,46 & 3,80 & 2,30 & 277,24 & 11066,70 & 1536,57 & 16,88 & 161,68 & 3725,52 & 2199,20 & 5,63 & 47,20 \\
\hline 4 & 307,58 & 32,61 & 23223,80 & 0,49 & 3,02 & 5,84 & 2,26 & 443,04 & 12570,52 & 1667,82 & 21,02 & 148,07 & 4047,57 & 2149,58 & 3,73 & 59,63 \\
\hline 5 & 252,75 & 34,10 & 24078,31 & 0,41 & 3,94 & 3,98 & 1,78 & 337,65 & 15058,09 & 1645,62 & 21,14 & 175,79 & 4061,27 & 2088,83 & 3,60 & 45,01 \\
\hline
\end{tabular}

DA: Deneme Alanı 
Ünver ve ark. (2009) ile Altınözlü ve ark. (2012) tarafından Türkiye'de yapılan araştırmalarda Alyssum pateri subsp. pateri bitkisinin Ni değişim aralık üst sınırının 1560 ppm olduğunu; Reeves ve Adıgüzel (2008) yaptıkları araştırmada Türkiye'de Alyssum pateri subsp. pateri bitkisinin ortalama Ni içeriğini 85 ppm olarak tespit edilmişken, bu araştırma sahasındaki bitki örneklerinde ortalama Ni konsantrasyonları 3741.66 ppm olduğu (Çizelge 2) tespit edilmiştir. Araştırma alanında benzer yüksek konsantrasyonlar $\mathrm{Al}, \mathrm{Ca}, \mathrm{K}, \mathrm{Mg}, \mathrm{Na}, \mathrm{Ni}$, $\mathrm{P}$ elementleri içinde tespit edilmiştir. Bu elementlerde toprakta bulunan miktarlardan çok daha fazlası bitki bünyesinde bulunmaktadır (Çizelge 2). Altınözlü ve ark (2012) yaptıkları çalışmada Alyssum pateri subsp. pateri bitkisinin $\mathrm{Cd}$ miktarının $<2.3$ ppm olduğunu belirtmişlerdir. Bu çalışmada ise Cd kapsamı $<0.96 \mathrm{ppm}$ olarak tespit edilmiştir. Bu bölgede söz konusu bitki Cd bakımından hiperakümülatör özellikte olmadı̆̆ anlaşılmıştır. Ancak bitki bünyesinde çok yüksek miktarlara varan Ca (24078.31ppm) ve K (15058.09 ppm) birikimi tespit edilmiştir (Şekil 6). Bölgedeki Ca kaynağı Koçali Karmaşığı (JKk) içerisinde bulunan kristalize kireçtaşlarıdır.

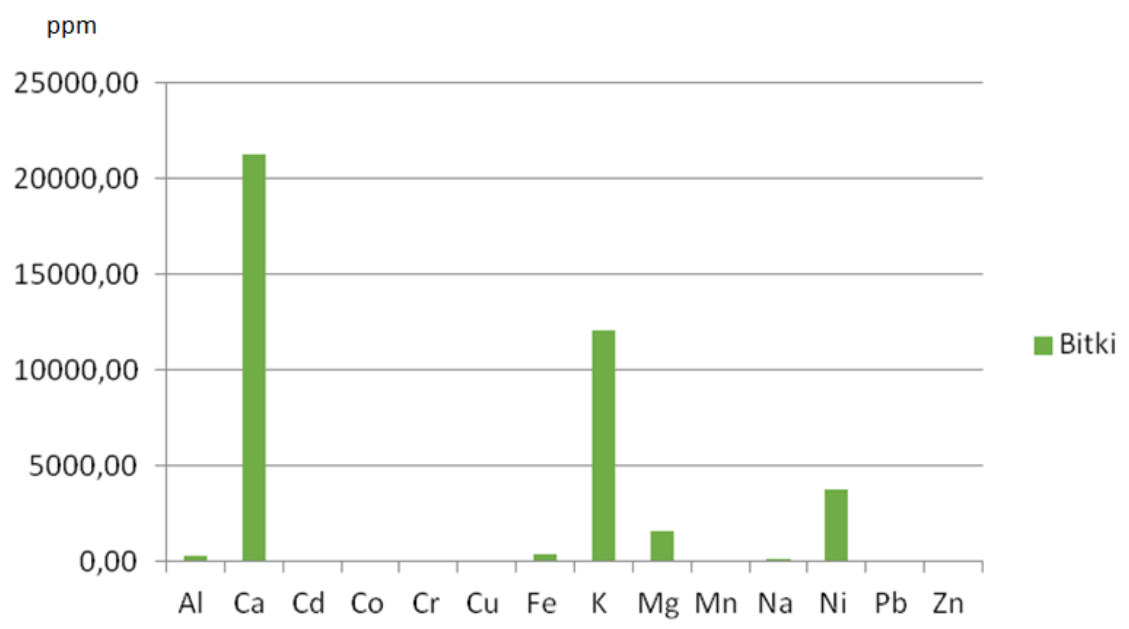

Şekil 6. Bitki örneklerinde bazı toplam makro, mikro elementler ve ağır metal konsantrasyonları

Bitki ve toprak örneklerinin toplam makro, mikro elementler ve ağır metal kapsamları arasında $\mathrm{R}^{2}=0.73$ gibi önemli ilişkiler belirlenmiştir (Şekil 7). Bu durumda bitkideki yüksek konsantrasyonun toprağa bağımlı olduğunu göstermektedir.

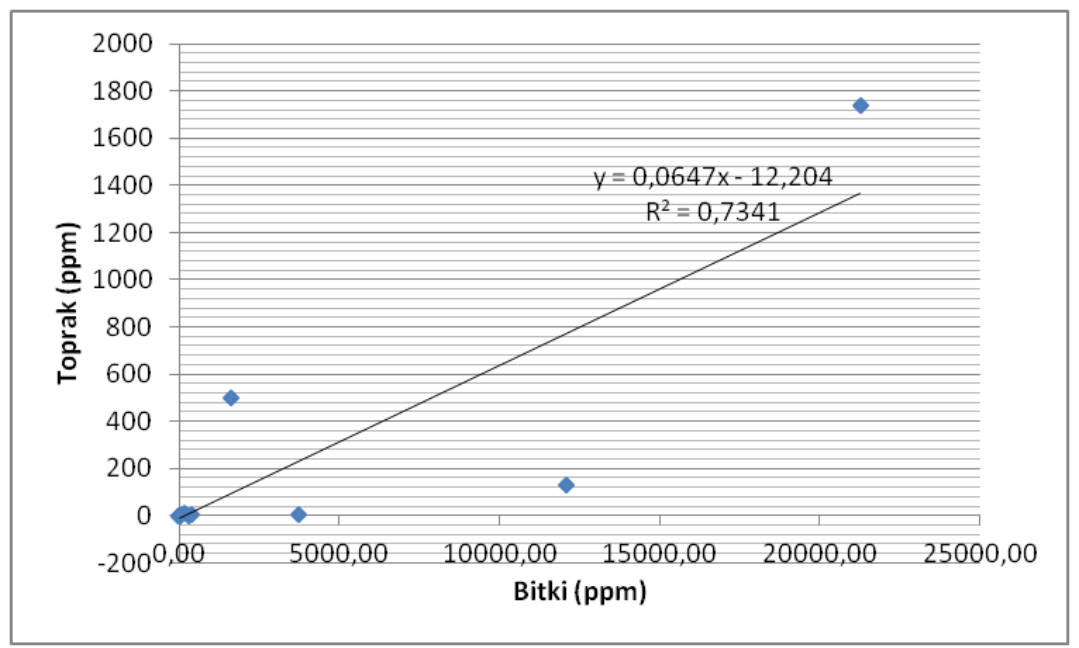

Şekil 7. Bitki ve toprak örneklerinde bazı toplam makro, mikro elementler ve ağır metal konsantrasyonları arasındaki ilişkiler

Bitki üzerinde oluşan Gal örneklerinde toplam makro, mikro elementler ve ağır metal konsantrasyonları incelenmiştir. Gal oluşumlarının da neredeyse bitki kadar $\mathrm{Ni}$, Ca ve $\mathrm{K}$ kapsamına sahip oldukları tespit edilmiştir. Gal oluşumunda en yüksek Ni kapsamı 3653.62 ppm, K kapsamı en yüksek 26340.08 ppm, Ca kapsamı 22687.63 ppm ve Mg kapsamı 1710.80 ppm olarak belirlenmiştir (Çizelge 3 ve Şekil 8). 
Çizelge 3. Gal örneklerinde toplam makro, mikro elementler ve ağır metal konsantrasyonları

\begin{tabular}{|c|c|c|c|c|c|c|c|c|c|c|c|c|c|c|c|c|}
\hline \multirow{2}{*}{$\mathrm{DA}$} & $\mathrm{Al}$ & $\mathrm{B}$ & $\mathrm{Ca}$ & $\mathrm{Cd}$ & Co & $\mathrm{Cr}$ & $\mathrm{Cu}$ & $\mathrm{Fe}$ & $\mathrm{K}$ & $\mathrm{Mg}$ & $\mathrm{Mn}$ & $\mathrm{Na}$ & $\mathrm{Ni}$ & $\mathrm{P}$ & $\mathrm{Pb}$ & $\mathrm{Zn}$ \\
\hline & \multicolumn{16}{|c|}{ ppm } \\
\hline 1 & 197,50 & 39,53 & 22415,67 & 0,24 & 2,91 & 3,54 & 2,31 & 331,30 & 26340,08 & 1705,15 & 23,21 & 60,27 & 2997,02 & 2420,25 & 2,00 & 36,93 \\
\hline 2 & 226,89 & 38,55 & 201 & 0,16 & 2,38 & 5,01 & 2,15 & 387,48 & 8,58 & 5 & 23,95 & 64,97 & 0,57 & 2050,81 & 1,85 & 35,86 \\
\hline 3 & 234,29 & 42,39 & 19230,69 & 0,19 & 2,66 & 3,35 & 3,99 & 320,45 & 10481,25 & 1570,48 & 23,32 & 73,47 & 3010,96 & 2483,84 & 1,83 & 51,41 \\
\hline 4 & 273,46 & 49,72 & 22687,63 & 0,21 & 1,84 & 5,83 & 2,33 & 552,40 & 13999,30 & 1710,80 & 24,67 & 60,50 & 2945,08 & 2466,43 & 1,91 & 45,97 \\
\hline 5 & 222,17 & 53,54 & 20599,91 & 0,26 & 3,30 & 3,57 & 2,36 & 469,02 & 14267,48 & 1677,33 & 29,87 & 73,99 & 3653,62 & 2696,30 & 2,34 & 48,49 \\
\hline
\end{tabular}

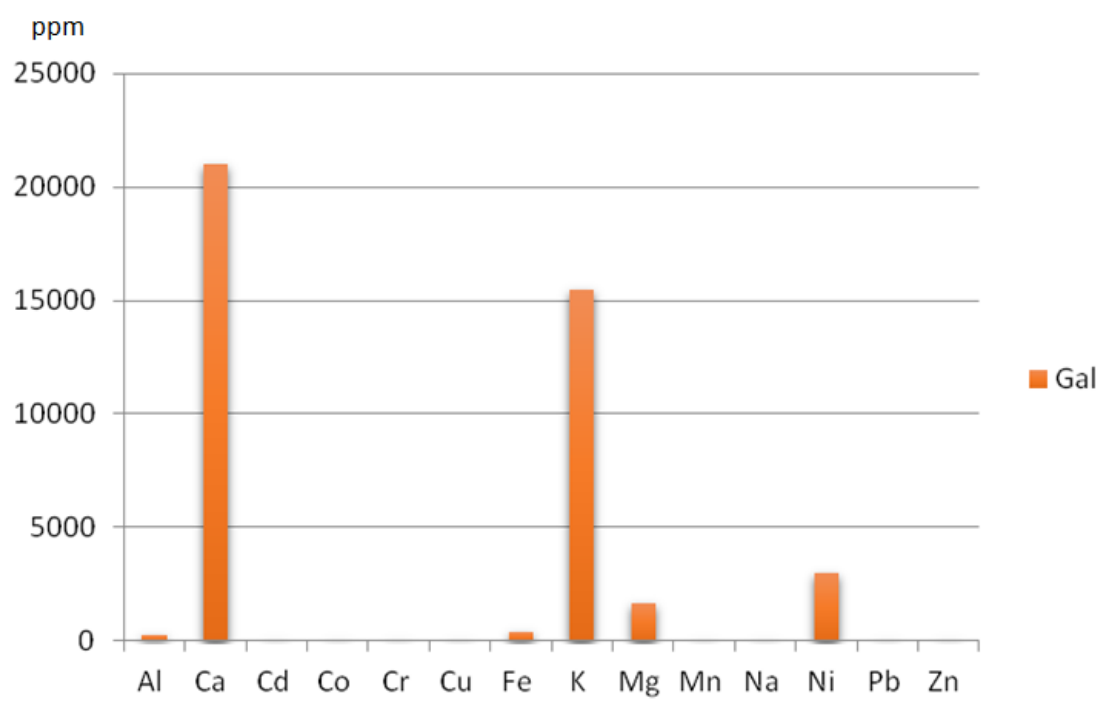

Şekil 8. Gal örneklerinde bazı toplam makro, mikro elementler ve ağır metal konsantrasyonları

Bitki ve gal örneklerinde tespit edilen toplam makro, mikro elementler ve ağır metal kapsamları arasında yapılan korelasyon testi sonucunda $\mathrm{R}^{2}=0.98$ gibi önemli ilişki düzeyi belirlenmiştir (Şekil 9). Bu durum gal bünyesindeki yüksek konsantrasyonun bitkiye bağımlı olduğunu göstermektedir.

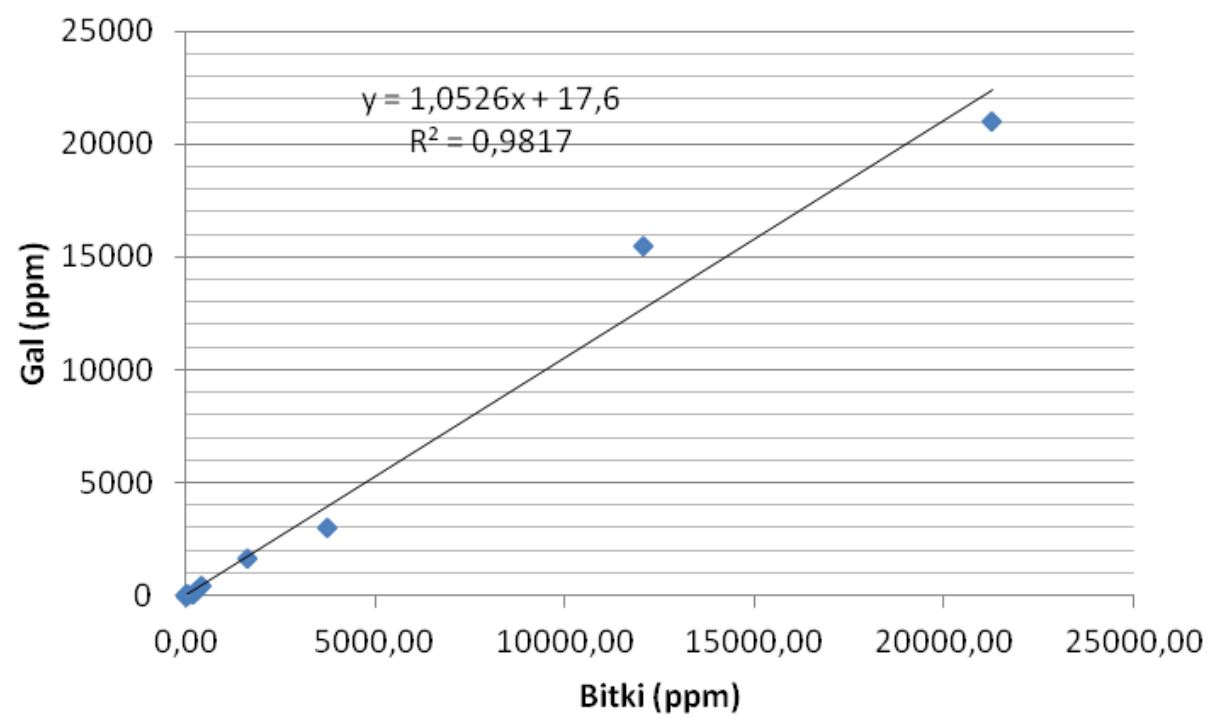

Şekil 9. Bitki ve gal örneklerinde tespit edilen bazı toplam makro, mikro elementler ve ağır metal konsantrasyonları arasındaki ilişkiler

Gal oluşumu ve bitki bünyesindeki toplanan elementlerle toplandığında hiperakümülator özellik daha güçlenmiş olmaktadır. Bu iki (bitki ve gal) özelik toplandığında Ni kapsamı en yüksek 6767.11 ppm, Ca kapsamı 42282.85ppm, Mg 3270.73 ppm ve K kapsamı 27563.63 ppm olarak belirlenmiştir (Şekil 10). 


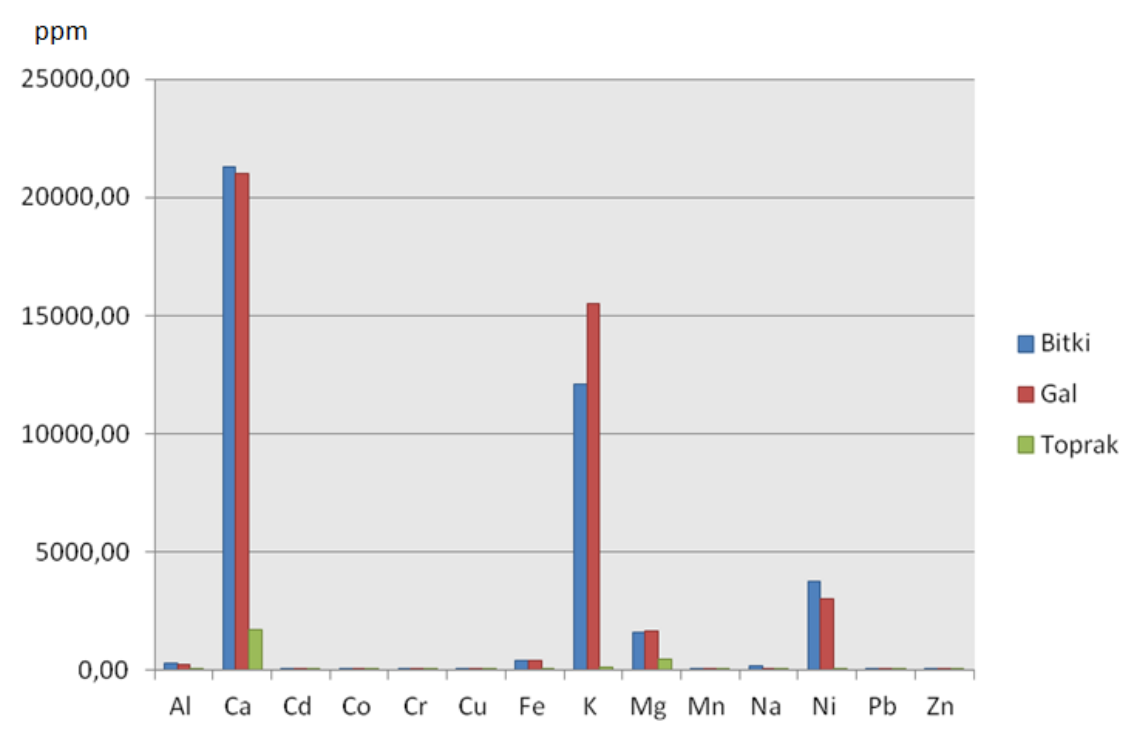

Şekil 10. Toprak, bitki ve gal örneklerinde bazı toplam makro, mikro elementler ve ağır metal konsantrasyonları

Ağır metalleri bünyesinde toplayabilen Brassicaceae familyasından A. Pateri subsp. pateri, A. corsicum, A. peltarioides subsp. peltarioides, A. peltarioides subsp. virgatiforme, Alyssum tortuosum, A. Sibiricum, A. murale gibi bir çok bitki mevcuttur (Abou-Shanab ve ark., 2006; Zhang ve ark., 2007; Reeves ve Adıgüzel, 2008). Bitki kullanılarak yapılan ıslah çalışmalarında (fitoremediasyon), hiperakümülatör yani ağır metal toplayıcı türlerin, değişen çevre koşullarına göre adaptasyon yeteneklerine ve biyokütle özelliklerine bağlıdır (Terzi ve Yıldız, 2011). Bitkinin ekolojik, fizyolojik ve moleküler özelliklerinin iyi anlaşılmasının yanı sıra önemli olan diğer bir husus bu bitkilerin hasat edildikten sonra arıtma süreçlerinin planlanmasıdır (Chen ve ark., 2000; Khan ve ark., 2000).

\section{Sonuç}

Araştırma alanında Alyssum pateri subsp. pateri bitkisinin Ni toplama kapasitesi bitki bünyesinde (4061.27 ppm) üzerindeki gal oluşumuyla (3653,62 ppm) beraber çok yüksek değerlere ulaşmıştır (7714.89 ppm). Aynı zamanda bünyesinde yüksek miktarda bitki Ca (24078.31ppm) ve K (15058.09 ppm) elementleri de tespit edilmiştir. Bitkide meydana gelen gal oluşumlarının da bitki kadar $\mathrm{Ni}$, Ca ve $\mathrm{K}$ kapsamı bakımından hiperakümülatör özellik taşıdığı belirlenmiştir. Araştırma alanı özellikle serpantinit bakımdan zengin ultramafik topraklar üzerinde yapılan ağaçlandırma faaliyetlerinde başlıca kullanılan tür Pinus brutia var. elderica dır. Bu türe ait bireyler zaman zaman tamamen kuruyarak ortamı terk etmeye başlamışlardır. Bu alanda Pinus brutia var. elderica türünün yirmi yıldan fazla bir süredir yaşayabilmesinin en önemli nedeni, alanda doğal olarak bulunan hiperakümülatör bitkilerden Alyssum pateri subsp. Pateri'nin yoğun bir şekilde bulunmasından kaynaklandığı düşünülmektedir.

$\mathrm{Bu}$ araştırma ile ağır metal toplayıcı bitki türlerinin tolerans sınırlarının farklı coğrafyalarda değişim gösterdiği anlaşılmış olup, bu sınırların belirlenmesi özellikle fitoremediasyon yöntemi olan bitkilerle ıslah çalışmalarının temelini oluşturmaktadır. Tek başına ya da farklı yöntem kombinasyonları ile beraber fitoremediasyon düşük ya da orta seviyeli kirlenmenin ya da kirletici ıslahının ekonomik ve aynı zamanda doğal bir parçası olabilir. Önemli olan bu süreçlerin planlanarak yürütülmesi ve sonucunda ağır metallerin etkilerinin tolere edilebilir seviyelere çekilmesini sağlamaktır.

\section{Kaynaklar}

Abou-Shanab RAI, Angle JS, Chaney RL, 2006. Bacterial inoculants affecting nickel uptake by Alyssum murale from low, moderate and high Ni soils. Soil Biology and Biochemistry, 38(9): 2882-2889.

Adıgüzel N, Reeves RD, 2002. A new nickel-accumulating species of Alyssum (Cruciferae) from Western Turkey. Edinburgh Journal of Botany 59(02):215 - 219.

Alexander EB, 2009. Soil and vegetation differences from peridotite to serpentinite. Northeastern Naturalist 16(5):178192.

Altınözlü H, Karagöz A, Polat T, Ünver İ, 2012. Nickel hyperaccumulation by natural plants in Turkish serpentine soils. Turkish Journal Of Botany, 36: 269-280.

Anacker BL, Harrison SP, 2012. Climate and the evolution of serpentine endemism in California. Evolutionary Ecology 26:1011-1023. 
Anonim, 1982. Methods of Soil Analysis- Part II, Chemical and Microbiological Properties, Argonomy Monograph No:9 323-336, ASA-SSSA, Medison, Wisconsin, USA.

Anonim, 1992. Orman Genel Müdürlüğü. Yeşil Kuşak Ağaçlandırma Çalışmaları, Tamim No:10.

Anonim, 2019. Toprak Kirliliğinin Kontrolü Yönetmeliği. Çevre ve Orman Bakanlı̆̆ http://www.resmigazete.gov.tr/eskiler/2005/05/20050531-6.htm Erişim tarihi: 12.09.2019.

Antonkiewicz J, Jasiewicz C, 2002. The use of plants accumulating heavy metals for detoxication of chemically polluted soils. Electronic Journal of Polish Agricultural Universities, 5(1).

Ateş Ş, Osmançelebioğlu R, Özata A, Karakaya FG, Aksoy A, Mutlu G, Duman TY, Özerk OC, Yeleser L, Çiçek İ, 2008. Kahramanmaraș İli ve Kentsel Alanların (il-iliçe Merkezleri) Yerbilim Verileri, Ankara.

Avcı M, 2005. Çeşitlilik ve Endemizm Açısından Türkiye'nin Bitki Örtüsü. İstanbul Üniversitesi Edebiyat Fakültesi Dergisi, 13:27-55.

Aybar M, Bilgin A, Sağlam B, 2015. Fitoremediasyon Yöntemi İle Topraktaki Ağır Metallerin Giderimi. Doğal Afetler ve Çevre Dergisi. 1(1-2): 59-65.

Batianoff GN, Singh S, 2001. Central Queensland serpentine landforms, plant ecology and endemism. South African Journal of Science 97:495-500.

Bouyoucos GJ, 1962. Hydrometer method improved for making particle size analyses of soils. Agronomy Journal 54: 464-465.

Boyd RS, Jaffré T, Odom JW, 1999. Variation in nickel content in the nickel-hyperaccumulating shrub Psychotria douarrei (Rubiaceae) from New Caledonia. Biotropica, 31: 403.

Brady KU, Kruckeberg AR, Bradshaw Jr H D, 2005. Evolutionary ecology of plant adaptation to serpentine soils. Annual Review of Ecology, Evolution, and Systematics, 36: 243-266.

Brooks RR, 1987. In Serpentine and Its Vegetation, ed.TR Dudley. Portland, OR: Dioscorides. 454 pp.

Brooks RR, Yang XH, 1984. Elemental levels and relationships in the endemic serpentine flora of the Great Dyke, Zimbabwe and their significance as controlling factors for this flora. Taxon, 33:392-99.

Chen HM, Zheng CR, Tu C, Shen ZG, 2000. Chemical methods and phytoremediation of soil contaminated with heavy metals, Chemosphere, 41, 229-234.

Demirsoy A, 1999. Yaşamın Temel Kuralları, Omurgasızlar/Böcekler, Entomoloji. 6. Baskı., s.272-274,

Dudley TR, Alyssum L. In: Davis, P.H. 1965. Flora of Turkey and The East Aegean Island, Volume 1, pp.399-400, Edinburg at the University Press.

EPA, 2000. Environmental Protection Agency, Introduction of phytoremediation, epa/600/R-99/107, Cincinati, Ohio, U.S.A2000: 72.

Jaffré T, L'Huillier L, 2010. La vegetation des roches ultramafiques ou terrains miniers. In: L'Huillier L, Jaffré T, Wulf A (eds) Mines et environnement en Nouvelle-Calédonie: les milieux sur substrats ultramafiques et leur restauration. IAC Ed, Noumea.

Janzen HH, 2004. Carbon cycling in earth systems-a soil science perspective. Agriculture, Ecosystems \& Environment, 104:399-417.

Khan AG, Kuek C, Chaudhry TM Khoo CS, Hayes WJ. 2000. Role of plants, mycorrhizae and phytochelators in heavy metal contaminated land remediation, Chemosphere, 41, 197-207.

Kocaer FO, Başkaya HS, 2003. Metallerle Kirlenmiş Toprakların Temizlenmesinde Uygulanan Teknolojiler, Uludağ Üniversitesi Mühendislik-Mimarlık Fakültesi Dergisi, Cilt 8, Sayı 1.

Kruckeberg AR, 1954. The ecology of serpentine soils: A symposium. III. Plant species in relation to serpentine soils. Ecology 35:267- 74 .

Kruckeberg AR 1985. California Serpentines:Flora, Vegetation, Geology, Soils, and Management Problems. Berkeley: Univ. Calif. Press. 180 pp.

Kruckeberg AR, Adıgüzel N, Reeves RD, 1999. Glimpses pf flora and ecology of Turkish (Anatolian) serpantines. The Karaca Arboretum Magazine 5: 67-86.

Lasat MM, 2000. Phytoextraction of metals from contaminated soil: A review of plant/ soil/ metal interaction and assessment of pertinent Agronomic Issues. Journal of Hazardous Substance Research, 2(5), 1-25.

Laz B, Babur E, Akpınar DM, Avgın SS, 2018. Kahramanmaraş-Elmalar Yeşil Kuşak Ek-3 Plantasyon Sahasında Görülen Biyotik ve Abiyotik Zararlıların Tespiti, Kahramanmaraş Sütçü Imam Üniversitesi Tarım ve Doğa Dergisi 21(6):926-935.

MTA, 2015. Türkiye Jeoloji ve Formasyon Haritası. Maden Tetkik Arama Genel Müdürlüğü Yayınları. Ankara http://www.mta.gov.tr/v3.0/hizmetler/jeoloji-haritalari

Mulligan CN, Yong RN, Gibbs BF, 2001. Remediation technologies for metalccontaminated soils and groundwater: an evaluation, Engineering Geology, 60, 193-207.

Mutlu B, 2012. Alyssum. Şu sitede: Bizimbitkiler (2013). <http://www.bizimbitkiler.org.tr>, [er. tar.: 09.09.2019].

Özdeniz E, Özbey BG, Kurt L, Bölükbaşı A, 2017. Serpantin Ekolojisi ve Türkiye Serpantin Florası'na Katkılar. Toprak Bilimi ve Bitki Besleme Dergisi, 5 (1): 22 - 33.

Palm ER, Van Volkenburgh E, 2014. Physiological adaptations of plants to serpentine soils. In: Rajakaruna N, Boyd RS, Harris TB (eds) Plant ecology and evolution in harsh environments. Nova Science Publishers, Hauppauge.

Proctor J, 1970. Magnesium as a toxic element. Nature, 227:742-43. 
Proctor J, 1971. The plant ecology of serpentine. II. Plant responses to serpentine soils. Journal of Ecology 59:397-410.

Proctor J, Woodell SRJ, 1975. The ecology of serpentine soils. Advances in Ecological Research 9:255- 365.

Rajakaruna N, 2004. The edaphic factor in the origin of species. International Geology Review 46:471-478.

Raskin I, Kumar N, Dushenkov S, Salt D, 1994. Bioconcentration of metals by plants, Current Opinion in Biotechnology, 5:285-290.

Reeves RD, Kruckeberg AR, Adıgüzel N, Kramer U, 2001. Studies on the flora of serpanrine and other metalliferous areas of Western Turkey. South African Journal of Science, 97: 513-517.

Reeves RD, Adıgüzel N, 2008. The nickel hyperaccumulating plants of the serpentines of Turkey and adjacent areas: A review with new data. Turkish Journal of Biology, 32: 143-153.

Terzi H, Yıldız M, 2011. Ağır metaller ve fitoremediasyon: fizyolojik ve moleküler mekanizmalar, Afyon Kocatepe Üniversitesi Fen Bilimleri Dergisi, 11(2011), 1-22.

Ünver İ, Madenoğlu S, Özbek K, 2009. Available Ni potentials of Batıern Anadolu. International Geology Symposium, 6-9 Şubat 2009, MTA Gn Md Kültür Sitesi, Ankara, sf: 146-153.

Vithanage M, Rajapaksha AU, Oze C, Rajakaruna N, Dissanayake CB, 2014. Metal release from serpentine soils in Sri Lanka. Environmental Monitoring and Assessment 186(6):3415-3429.

Vlamis J, Jenny H, 1948. Calcium Deficiency in Serpentine Soils as Revealed by Adsorbent Technique. Science, 107(2786): 549 .

Walker RB, 1948. A study of serpentine soil infertility with special reference to edaphic endemism. Univ. Calif., Berkeley, PhD thesis, $101 \mathrm{pp}$.

Walker RB, Walker HM, Ashworth PR, 1955. Calcium-magnesium nutrition with special reference to serpentine soils. Plant Physiology 30: 214-21.

Walkley A, Black A, 1934. An examination of the Degtjareff method for determining soil organic matter, and proposed modification of the chromic acid titration method. Soil Science 37: 29-38.

Zhang L, Angle JS, Chaney RL, 2007. Do high-nickel leaves shed by the nickel hyperaccumulator Alyssum murale inhibit seed germination of competing plants? New Phytologist 173(3): 509-516. 